RH: LISTERIA MONOCYTOGENES INFECTION IN HEDGEHOGS

\title{
LISTERIA MONOCYTOGENES INFECTION OF FREE-LIVING WESTERN EUROPEAN HEDGEHOGS (ERINACEUS EUROPAEUS)
}

Helle B. Hydeskov, M.Sc., D.V.M., M.Vet.Med., M.R.C.V.S., Corinne F. L. Amar, Ph.D., Julia

Rodriguez-Ramos Fernandez, D.V.M., Dipl. E.C.Z.M. (Wildlife Population Health), Dipl. A.C.V.P., M.R.C.V.S., Shinto K. John, M.L.T., Shaheed K. Macgregor, H.Tec., M.Sc., C.Sci., Andrew A. Cunningham, B.V.M.S., Dipl. E.C.Z.M. (Wildlife Population Health), Ph.D.,

F.R.C.V.S. and Becki Lawson, M.A., Vet.M.B., M.Sc., Ph.D., Dipl. E.C.Z.M. (Wildlife Population Health), M.R.C.V.S.

From Institute of Zoology, Zoological Society of London, Regents Park, London, NW1 4RY, United Kingdom (Hydeskov, John, Cunningham, Lawson); Veterinary Epidemiology,

Economics and Public Health Group, Royal Veterinary College, Hawkshead Lane, North Mymms, Hatfield, AL9 7TA, United Kingdom (Hydeskov); Gastrointestinal Bacterial Reference Unit, Public Health England, 61 Colindale Avenue, London, NW9 5EQ, United Kingdom (Amar); IDEXX Laboratories, Grange House, Sandbeck Way, Wetherby, LS22 7DN, United Kingdom (Rodriguez-Ramos Fernandez); Living Collections, Zoological Society of London, Regents Park, London, NW1 4RY, United Kingdom (Macgregor). Correspondence should be directed to Dr. Hydeskov (helle.hydeskov@ioz.ac.uk). 
Abstract: Listeria monocytogenes is a ubiquitous environmental bacterium that causes

25 disease in a wide range of species. Infection with this pathogen is most frequently diagnosed in ruminant livestock, but is also known to infect people and occasionally wildlife. Post-mortem examinations of Western European hedgehogs (Erinaceus europaeus) in Great Britain (20112017) identified five $(5 / 266,2 \%, 95 \%$ confidence interval: $0.8-4.3 \%)$ animals with $L$. monocytogenes infection. The L. monocytogenes isolates comprised three serogroup 1/2a and two serogroup 4 from three Multilocus Sequence Types (2, 37 and 121), all of which were different by single nucleotide polymorphism analysis indicating they were distinct and epidemiologically-unrelated. These findings are consistent with hedgehogs contracting sporadic infection from the environment, perhaps through eating soil-dwelling invertebrates. Examination of data from scanning surveillance programs focused on other British wildlife species indicates that the hedgehog is one of the wildlife species from which L. monocytogenes has been most frequently identified to date in Great Britain. However, further studies of multiple taxa with comparable sampling efforts are required to assess the relative frequency of L. monocytogenes infection in different wildlife species. The bacterium was isolated from extra-intestinal sites in multiple hedgehogs which may indicate septicemia. However, histological examination was limited and could not discriminate subclinical infection from disease (i.e. listeriosis). Whilst $L$. monocytogenes is a source of zoonotic infection, disease in people is typically contracted from the ingestion of contaminated foods. The risk to immunocompetent people of contracting listeriosis from hedgehogs is considered very low to negligible. 
Key words: Erinaceidae, Erinaceus europaeus, Listeria monocytogenes, Western European hedgehog, whole genome sequencing, zoonosis.

50

\section{INTRODUCTION}

Listeria monocytogenes, the causative agent of listeriosis, is a Gram-positive rod to coccobacillus. This bacterium is widely distributed in the environment, particularly in soil and decomposing plant material. ${ }^{5}$ Listeriosis is primarily reported in domestic ruminants, but is also

55 known to affect people and occasionally wildlife including species present in Great Britain. ${ }^{7,11,19,20}$ Disease presentation can be similar across mammalian species and includes septicemia, encephalitis, and abortion. ${ }^{5,7,19}$ Listeria monocytogenes can also be carried in the gastrointestinal tract of individuals without apparent disease. ${ }^{5,7}$

In people, listeriosis typically affects pregnant women, neonates, and other

60 immunocompromised individuals. ${ }^{13}$ It is usually contracted through ingestion of contaminated food and rarely via contact with infected animals or their feces. ${ }^{5,17}$ In England and Wales, the number of human cases per annum is relatively low (143 cases in 2017) in comparison to other food-borne zoonoses (Public Health England (PHE), unpubl. data). Although a rare disease, the case fatality rate in people is $20-30 \% .^{13}$

65 The Western European hedgehog (Erinaceus europaeus), hereafter hedgehog, is a nocturnal insectivorous mammal found throughout Western and Northern Europe. ${ }^{1}$ Listeria monocytogenes infection has previously only been reported from a single hedgehog in France as part of a targeted survey for this bacterium. ${ }^{2}$ No information was provided on the animal's history or whether evidence of listeriosis was detected. 
A scanning surveillance program for disease in free-living hedgehogs in Great Britain has been conducted since 2011. To date, this program has detected infection of hedgehogs with multiple zoonotic pathogens, e.g. Cryptosporidium parvum and Salmonella Enteritidis. ${ }^{9,18}$

The aims of this study were three-fold: first, to investigate the findings of hedgehogs examined post mortem from which L. monocytogenes was isolated, and to further appraise the

75 clinical significance of the bacterial infection, through microscopic examination where possible. Second, to characterize the L. monocytogenes isolates from hedgehogs using molecular methods and compare them with those which most frequently affect people and livestock in Great Britain. Third, to compare our findings with data on L. monocytogenes infection from other British wildlife species to appraise the occurrence of this pathogen across different taxa.

\section{MATERIALS AND METHODS}

Post-mortem examination

Systematic post-mortem examinations were conducted on 266 hedgehogs found dead in the

85 wild or in a wildlife rehabilitation center in Great Britain, 2011-2017, as described by Franklinos et al. (2015). ${ }^{8}$ Carcasses were examined fresh where possible, or stored at $-20^{\circ} \mathrm{C}$ until examination. For each animal, information was recorded on the location and habitat type where found, sex, age class (based on dentition), body weight, subjective assessment of body condition (based on fat deposits) and the amount of time spent in a wildlife rehabilitation center (if 90 applicable).

Parasitology and microbiology 
Microscopic examination of $0.85 \%$ saline wet mount preparations (E \& O Laboratories Ltd., Bonnybridge, FK4 2HH, United Kingdom) of bronchial and small intestinal contents was routinely conducted. Microbiological testing on a skin swab, a throat swab (from June 2015 onwards only), liver tissue, small intestinal tract contents, and on any macroscopic lesions detected was also routinely conducted from each hedgehog. Each sample was cultured onto Columbia 5\% horse blood agar plates and incubated aerobically and anaerobically. Samples of small intestinal tract contents were cultured directly onto Campylobacter selective blood free agar plates and incubated micro-aerophilically, cultured directly onto xylose-lysinedesoxycholate agar plates and incubated aerobically, and enriched in selenite broth for 48 hours at $37^{\circ} \mathrm{C}$ prior to being sub-cultured onto xylose-lysine-desoxycholate agar plates and incubated aerobically. Lung tissue when sampled was cultured onto a chocolate horse blood agar plate and

105 incubated $\mathrm{CO}_{2}$ (all from Oxoid Ltd., Basingstoke, RG24 8PW, United Kingdom). All plates were incubated at $37^{\circ} \mathrm{C}$ and observed after 1,2 and 5 days. The identification of L. monocytogenes was based on Gram's stain (Pro-Lab Diagnostics Inc., Wirral, CH62 3QL, United Kingdom), colonial morphology and biochemical reaction profile using API CORYNE identifications strips (bioMérieux UK Ltd., Basingstoke, RG22 6HY, United Kingdom).

Whole genome sequencing

DNA was extracted from purified colonies of L. monocytogenes using the QIAsymphony® automated extraction platform following a pre-lysis step with lysozyme and Proteinase K (all 115 Qiagen Ltd., Manchester, M15 6SH, United Kingdom). Whole genome sequencing (WGS) was 
performed as described by Dallman et al. (2015). ${ }^{4}$ The serogroups, inferred from the sequence, were assigned according to the Doumith et al. (2004) classification. ${ }^{6}$ The Multilocus Sequence Type (MLST), as defined by the Pasteur Scheme, ${ }^{15}$ was extracted from WGS data (Institut Pasteur MLST and MLST whole genome databases, http://bigsdb.pasteur.fr/listeria/). Single nucleotide polymorphism (SNP) analyses were performed using SnapperDB, a set of tools to store bacterial variant data and facilitate reproducible and scalable analysis of bacterial populations. $^{3}$

Histopathology

When tissues fixed in neutral buffered 10\% formalin (Genta Medical, York, YO26 7QF, United Kingdom) were available from hedgehogs with L. monocytogenes infection, they were processed for histological examination and stained with hematoxylin and eosin using routine methods (IDEXX Laboratories Ltd., Wetherby, LS22 7DN, United Kingdom). Gram, Ziehl130 Neelsen and periodic acid-Schiff staining (all IDEXX Laboratories Ltd.) was conducted on a subset of tissue sections where indicated by the presence of lesions. Tissues from one case were not saved (case 1).

\section{RESULTS}

Listeria monocytogenes was isolated from the liver and a range of other tissues from five ( $2 \%, 95 \%$ confidence interval: $0.8-4.3 \%)$ of 226 hedgehogs examined (Tables 1-4). The majority of the Listeria-positive samples yielded pure/confluent/mixed isolates of the bacterium (Table 2). Infected animals comprised a mix of age class (two juvenile, three adult), sex (two female, three 
male) and body condition (three thin, two normal) (Table 1). The five Listeria-positive hedgehogs died March to November, 2013-2016; three had died in wildlife rehabilitation centers. Two of the hedgehogs were observed by members of the public showing signs of ill health, before being found dead in the field. Three of the hedgehogs were found by members of the public, and presented for treatment at wildlife rehabilitation centers. The clinical signs observed in all of the Listeria-positive hedgehogs included lethargy and/or acting abnormally (e.g. active during the day). Four were from different sites in rural habitats and one from a suburban area. In each case, a single hedgehog was affected per site. Parasitology and microbiology results are presented in Table 2. Results from the macroscopic and microscopic examinations are presented in Table 3. No bacteria consistent with L. monocytogenes were observed on histopathological examination of tissues with microscopic lesions (cases 4 and 5). Case 4 had a single focus of necrotizing hepatitis; no infectious organisms were noted on Gram, Ziehl-Neelsen, or periodic acid-Schiff staining. Case 5 had pleuritis with Gram-negative intralesional bacteria. Concurrent disease considered sufficient to contribute to the cause of death, was diagnosed in four of the five hedgehogs (Table 3). The cause of death was undetermined for the fifth hedgehog.

WGS identified L. monocytogenes serogroup 1/2a, MLST 37 from two hedgehogs, $L$. monocytogenes serogroup 1/2a, MLST 121 from one, and L. monocytogenes serogroup 4, MLST 2 from the remaining two animals (Table 4). The two MLST 37 isolates had between 10 and 25 SNPs and the two MLST 2 isolates had between 50 and 100 SNPs.

\section{DISCUSSION}

In this study, L. monocytogenes infection from multiple hedgehogs in Great Britain was identified and the isolates were characterized. Infected hedgehogs had a wide geographical 
distribution and both age classes and sexes were affected. In each case, the L. monocytogenes isolate was genetically different by MLST typing and/or by SNP analysis indicating that the cases were epidemiologically unrelated.

165 Meaningful histopathological interpretation was precluded for most of the infected animals due to autolysis and/or freeze-thaw artifact, therefore it was not possible to assess whether $L$. monocytogenes was causing listeriosis. That the bacterium was isolated from extra-intestinal sites in all cases could indicate dissemination of the bacterium and septicemic listeriosis, which is the most common disease presentation in small mammals. ${ }^{11}$ Case 4 had L. monocytogenes in 170 the small intestine. Since no bacteria were found associated with the liver lesions in this animal, it is possible that it was a subclinical carrier of the bacterium, with liver invasion occurring postmortem. The etiology of the hepatic lesions in this animal remains undetermined. Optimal tissue preservation and immunohistochemistry would increase the likelihood of detecting listeriosis, if present.

175 Infections with pathogens other than L. monocytogenes were considered sufficient to have contributed to the cause of death in four of the Listeria-positive hedgehogs. Listeria monocytogenes tends to affect immunocompromised individuals, ${ }^{5}$ thus concurrent disease might have predisposed the hedgehogs to disseminated L. monocytogenes infection. Three of the hedgehogs had been admitted to wildlife rehabilitation centers prior to death. The two cases with available data on length of time in rehabilitation (cases 2 and 3) died within 48 hours of admission, therefore the findings are likely to represent the wild status rather than be a consequence of stress in captivity or nosocomial infection.

In addition to the hedgehog surveillance program, post-mortem and routine microbiological examinations of other free-living wild animals in Great Britain are conducted at the Institute of 
185 Zoology. To date, L. monocytogenes has not been isolated from circa 4,000 wild birds of circa 60 species (1992-2017) or from 728 cetaceans of 16 species (found stranded around the coast of England and Wales, 2004-2016) examined (unpubl. data). This pathogen was, however, isolated from two (7\%) of 29 Eurasian red squirrels (Sciurus vulgaris), where macroscopic lesions led to microbiological testing, 2004-2013. These two were emaciated adults from separate incidents. Listeria monocytogenes was recovered from consolidated lung tissue in one squirrel, and from an enlarged spleen and intussuscepted large intestine in the other (unpubl. data). Histological examination was not possible in either case, therefore, the significance of this bacterial infection through assessment of the presence of microscopic lesions could not be further investigated.

The Animal Plant and Health Agency also conducts scanning surveillance of British wildlife.

195 Of circa 1,000 wild mammal post-mortem examinations of 23 species, 2008-2017, L. monocytogenes was identified in five free-living Eurasian red squirrels, two captive European water voles (Arvicola amphibious) and one captive fallow deer (Dama dama) but from none of circa 90 hedgehogs (unpubl. data).

Based on our study and available data from the different British wildlife disease surveillance 200 programs, the hedgehog is one of the species from which L. monocytogenes infection has been most frequently detected to date. Given that the study utilizes a convenience sample (i.e. non randomized sampling) and comparison with data from other taxa and surveillance schemes is limited by heterogeneity in microbiological examination and sampling effort, further research is required to investigate the relative frequency of $L$. monocytogenes infection in the hedgehog as 205 compared with other British wildlife species to determine whether differential species susceptibility or exposure occurs. Hedgehogs typically eat soil-dwelling invertebrates, ${ }^{16}$ such as earthworms, thus providing a mechanism for exposure to L. monocytogenes. 
The hedgehog L. monocytogenes isolates were of the same serogroups and MLSTs detected in human and livestock listeriosis cases. ${ }^{5,12}$ PHE considers isolates of L. monocytogenes linked 210 within the same 0 to 5 SNP clusters to likely be from the same point source. ${ }^{12}$ The hedgehog isolates within each MLST had $\geq 10$ SNPs difference indicating that a common source was unlikely. No strains similar (i.e. within a 5 SNP cluster) to those isolated from the hedgehogs were identified in PHE surveillance database of human Listeria isolates.

Hedgehogs are the mammal species most frequently admitted to wildlife rehabilitation centers 215 in Great Britain. ${ }^{10}$ Hygiene precautions are recommended as a routine (e.g. wearing disposable, protective gloves during handling and washing hands afterwards), particularly for hedgehog carers who frequently handle hedgehogs. Immunocompromised people and pregnant women should take particular care when in contact with hedgehogs. Supplementary feeding of freeliving hedgehogs is an increasingly common practice; ${ }^{14}$ routine hand washing after feeding 220 hedgehogs is similarly recommended when this takes place. The risk to immunocompetent people of contracting L. monocytogenes infection from infected hedgehogs is considered very low to negligible.

Acknowledgments: The authors would like to thank the members of the public and wildlife 225 treatment and rehabilitation centers who submitted hedgehogs to the Garden Wildlife Health project, Institute of Zoology, Zoological Society of London for examination; Ricardo Castro Cesar de Sa, Timothy C. Hopkins, Lydia H. V. Franklinos, Katharina Seilern-Moy and Victoria A. Wilkinson (Zoological Society of London) for assistance with pathological examinations; Rob Deaville (Zoological Society of London) for providing information on cetacean surveillance;

230 Disease Risk Analysis and Health Surveillance for Interventions partnership with Natural 
England for providing information on Eurasian red squirrel surveillance; J. Paul Duff (Animal and Plant Health Agency, Diseases of Wildlife Scheme, United Kingdom) for providing information on Great Britain wildlife disease surveillance; Philippe Gourlay (Wildlife Health Centre, Nantes, France) for assistance with French translation.

\section{LITERATURE CITED}

1. Amori G. Erinaceus europaeus. The IUCN Red List of Threatened Species 2016 [Internet]. 2016 [cited 2018 May 07];e.T29650A2791303. Available from doi: http://dx.doi.org/10.2305/IUCN.UK.2016-3.RLTS.T29650A2791303.en

2. André P. Isolement de Listeria monocytogenes chez un hérisson. Ann Inst Pasteur. $1966 ; 111: 225-226$.

3. Dallman T, Ashton P, Schafer U, Jironkin A, Painset A, Shaaban S, Hartman H, Myers R, 245 Underwood A, Jenkins C, Grant K. SnapperDB: A database solution for routine sequencing analysis of bacterial isolates. Bioinformatics [Internet]. 2018 [cited 2018 May 07];bty212. Available from doi: 10.1093/bioinformatics/bty212

4. Dallman TJ, Byrne L, Ashton PM, Cowley LA, Perry NT, Adak G, Petrovska L, Ellis RJ, 250 Elson R, Underwood A, Green J, Hanage WP, Jenkins C, Grant K, Wain J. Whole-genome Sequencing for National Surveillance of Shiga Toxin-Producing Escherichia coli O157. Clin Infect Dis. 2015;61(3):305-312. 
5. Dhama K, Karthik K, Tiwari R, Shabbir MZ, Barbuddhe S, Malik SVS, Singh RK.

255 Listeriosis in animals, its public health significance (food-borne zoonosis) and advances in diagnosis and control: a comprehensive review. Vet Q. 2015;35(4):211-235.

6. Doumith M, Buchrieser C, Glaser P, Jacquet C, Martin P. Differentiation of the Major Listeria monocytogenes Serovars by Multiplex PCR. J Clin Microbiol. 2008;42(8):3819-3822.

7. Ferroglio E. Listeria Infections. In: Gavier-Widén D, Duff JP, Meredith A (eds.). Infectious Diseases of Wild Mammals and Birds in Europe. Chichester, United Kingdom: Blackwell Publishing; 2012. p. 413-416.

8. Franklinos LHV, Efstratiou A, Macgregor SK, John SK, Hopkins T, Cunningham AA, Lawson B. Streptococcus pyogenes infection in a free-living European hedgehog (Erinaceus europaeus). EcoHealth. 2015;12(4):689-692. Macgregor SK, John SK, Pizzi R, Alejandro N, Ashton PM, Cunningham AA, de Pinna EM. Salmonella Enteritidis ST183: emerging and endemic biotypes affecting western European hedgehogs (Erinaceus europaeus) and people in Great Britain. Sci Rep [Internet]. 2018 [cited 2018 May 07];8:2449. Available from doi:10.1038/s41598-017-18667-2 
10. Molony SE, Dowding CV, Baker PJ, Cuthill IC, Harris S. The effect of translocation and temporary captivity on wildlife rehabilitation success: An experimental study using European hedgehogs (Erinaceus europaeus). Biol Conserv. 2006;130(4):530-537. Mammals. 3rd ed. Ames (IA): The Iowa State University Press; 2001. p. 502-505.

12. Nielsen EM, Björkman TJ, Kiil K, Grant K, Dallman T, Painset A, Amar C, Roussel S, Guillier L, Félix B, Rotariu O, Perez-Reche F, Forbes K, Strachan N. Closing gaps for performing a risk assessment on Listeria monocytogenes in ready-to-eat (RTE) foods: activity 3, the comparison of isolates from different compartments along the food chain, and from humans using whole genome sequencing (WGS) analysis. EFSA Supporting publications [Internet]. 2017 [cited 2018 May 07];2017:EN-1151. Available from doi:10.2903/sp.efsa.2017.EN-1151

13. de Noordhout CM, Devleesschauwer B, Angulo FJ, Verbeke G, Haagsma J, Kirk M, Havelaar A, Speybroeck N. The global burden of listeriosis: a systematic review and metaanalysis. Lancet Infect Dis. 2014;14(11):1073-1082.

14. Pettett CE, Moorhouse TP, Johnson PJ, Macdonald DW. Factors affecting hedgehog 295 (Erinaceus europaeus) attraction to rural villages in arable landscapes. Eur J Wildl Res [Internet]. 2017 [cited 2018 May 07];63:54. Available from doi:10.1007/s10344-017-1113-6 
15. Ragon M, Wirth T, Hollandt F, Lavenir R, Lecuit M, Le Monnier A, Brisse S. A New Perspective on Listeria monocytogenes Evolution. PLoS Pathog [Internet]. 2008 [cited 2018 May 300 07];4(9):e1000146. Available from doi:10.1371/journal.ppat.1000146

16. Rautio A, Isomursu M, Valtonen A, Hirvelä-Koski V, Kunnasranta M. Mortality, diseases and diet of European hedgehogs (Erinaceus europaeus) in an urban environment in Finland. Mamm Res. 2016;61(2):161-169.

305

17. Regan EJ, Harrison GAJ, Butler S, McLauchlin J, Thomas M, Mitchell S. Primary cutaneous listeriosis in a veterinarian. Vet Rec. 2005;157(7):207.

18. Sangster L, Blake DP, Robinson G, Hopkins TC, Sa RCC, Cunningham AA, Chalmers

310 RM, Lawson B. Detection and molecular characterisation of Cryptosporidium parvum in British European hedgehogs (Erinaceus europaeus). Vet Parasitol. 2016;217:39-44.

19. Tham W, Bannerman E, Bille J, Danielsson-Tham ML, Eld K, Ericsson H, Gavier-Widén D, Rocourt J, Mörner T. Listeria monocytogenes subtypes associated with mortality among 315 fallow deer (Dama dama). J Zoo Wildl Med. 1999;30(4):545-549.

20. Wuthe HH, Schönberg A. [Listeriosis in the European brown hare in northern Germany]. Berliner und Münchener Tierärztliche Wochenschrift [Berliner and Muenchener Tieraerztliche Wochenschrift]. 1999;112:98-99. 
Table 1. History and description of Western European hedgehogs (Erinaceus europaeus) isolated with Listeria monocytogenes in Great Britain 2013-2016.

\begin{tabular}{|c|c|c|c|c|c|}
\hline Case & $\begin{array}{l}\text { Month and year found dead, } \\
\text { carcass storage and carcass } \\
\text { condition status }\end{array}$ & $\begin{array}{l}\text { Age class } \\
\text { and sex }\end{array}$ & $\begin{array}{c}\text { Body condition class } \\
\text { and bodyweight }\end{array}$ & $\begin{array}{c}\text { Habitat type and } \\
\text { location }\end{array}$ & $\begin{array}{c}\text { History of time in } \\
\text { rehabilitation center? }\end{array}$ \\
\hline$\overline{1}$ & $\begin{array}{c}\text { 09/2013 } \\
\text { Frozen } \\
\text { Mild autolysis }\end{array}$ & $\begin{array}{l}\text { Juvenile } \\
\text { Female }\end{array}$ & $\begin{array}{l}\text { Thin } \\
245 \mathrm{~g}\end{array}$ & $\begin{array}{c}\text { Rural, Wiltshire, } \\
\text { England }\end{array}$ & No \\
\hline 2 & $\begin{array}{c}\text { 08/2015 } \\
\text { Frozen } \\
\text { Moderate autolysis }\end{array}$ & $\begin{array}{l}\text { Adult } \\
\text { Male }\end{array}$ & $\begin{array}{l}\text { Thin } \\
441 \mathrm{~g}\end{array}$ & $\begin{array}{c}\text { Suburban, } \\
\text { Merseyside, England }\end{array}$ & Yes, $<48$ hours \\
\hline 3 & $\begin{array}{l}\text { 11/2015 } \\
\text { Frozen }\end{array}$ & $\begin{array}{l}\text { Adult } \\
\text { Female }\end{array}$ & $\begin{array}{l}\text { Normal } \\
744 \mathrm{~g}\end{array}$ & $\begin{array}{c}\text { Rural, Bedfordshire, } \\
\text { England }\end{array}$ & Yes, $<48$ hours \\
\hline & Moderate autolysis & & & & \\
\hline 4 & $\begin{array}{l}\text { 03/2016 } \\
\text { Frozen }\end{array}$ & $\begin{array}{c}\text { Juvenile } \\
\text { Male }\end{array}$ & $\begin{array}{l}\text { Normal } \\
452 \mathrm{~g}\end{array}$ & $\begin{array}{c}\text { Rural, Denbighshire, } \\
\text { Wales }\end{array}$ & No \\
\hline & Moderate autolysis & & & & \\
\hline 5 & $\begin{array}{l}06 / 2016 \\
\text { Frozen }\end{array}$ & $\begin{array}{l}\text { Adult } \\
\text { Male }\end{array}$ & $\begin{array}{l}\text { Thin } \\
574 \mathrm{~g}\end{array}$ & $\begin{array}{c}\text { Rural, East Sussex, } \\
\text { England }\end{array}$ & $\begin{array}{c}\text { Yes, length of time } \\
\text { unknown }\end{array}$ \\
\hline & Moderate autolysis & & & & \\
\hline
\end{tabular}


Table 2. Parasitology and microbiology results from Western European hedgehogs (Erinaceus europaeus) isolated with Listeria monocytogenes in Great Britain 2013-2016.

\begin{tabular}{|c|c|c|}
\hline Case & Parasitology & $\begin{array}{c}\text { Organs tested on routine microbiology } \\
\text { (* denotes organs culture-positive for } L \text {. monocytogenes) } \\
\text { Other significant pathogens isolated }\end{array}$ \\
\hline \multirow[t]{5}{*}{1} & Ixodid ticks (skin) & Liver $^{* \mathrm{~b}}$, lung ${ }^{* \mathrm{~b}}$, urine, brain, small intestine, large intestine. \\
\hline & Crenosoma striatum adults and larvae (lung) & \\
\hline & Capillaria sp. ova (lung and intestinal contents) & \\
\hline & Acanthocephalans (mesenterium and intestinal & \\
\hline & serosa) & \\
\hline \multirow[t]{2}{*}{2} & Capillaria sp. ova (intestinal contents) & Skin*a, liver*b, mandibular abscess*b, small intestine. \\
\hline & & Pasteurella multocida (isolated from skin, liver, mandibular abscess) \\
\hline 3 & Ixodid ticks (skin) & Liver*c, throat ${ }^{* c}$, skin, small intestine. \\
\hline \multirow[t]{4}{*}{4} & Crenosoma sp. adults and larvae (lung) & Liver lesion*a, small intestine ${ }^{* c}$, liver, throat, skin, mesenteric lymph \\
\hline & & node \\
\hline & Capillaria sp. adults and ova (small intestine & \\
\hline & contents) & Staphylococcus aureus (isolated from skin) \\
\hline \multirow[t]{2}{*}{5} & Helminth larvae (lung and small intestinal contents) & Liver*d, heart*a ${ }^{* a}$ lung, small intestine, throat, skin. \\
\hline & Capillaria sp. ova (lung) & Candida albicans (isolated from throat) \\
\hline \multicolumn{3}{|c|}{ Few Listeria monocytogenes colonies. } \\
\hline \multicolumn{3}{|c|}{ Moderate mixed isolate with Listeria monocytogenes colonies. } \\
\hline \multicolumn{3}{|c|}{${ }^{\mathrm{c}}$ Confluent mixed isolate with Listeria monocytogenes predominating. } \\
\hline
\end{tabular}


335 Table 4. Listeria monocytogenes isolate serogroup, Multilocus Sequence Type (MLST) and SingleNucleotide Polymorphism (SNP) address from Western European hedgehogs (Erinaceus europaeus) isolated with Listeria monocytogenes in Great Britain 2013-2016.

\begin{tabular}{cccc}
\hline Case & Serogroup & Multilocus Sequence Type (MLST) & Single-Nucleotide Polymorphism (SNP) address \\
\hline 1 & 4 & 2 & 1.1 .4 .305 .323 .339 .376 \\
2 & 4 & 2 & 1.1 .283 .297 .313 .329 .365 \\
3 & $1 / 2 \mathrm{a}$ & 37 & 1.2 .2 .2 .123 .126 .130 \\
4 & $1 / 2 \mathrm{a}$ & 121 & 1.1 .17 .42 .473 .489 .605 \\
5 & $1 / 2 \mathrm{a}$ & 37 & 1.2 .2 .2 .16 .16 .16 \\
\hline
\end{tabular}

